\title{
Evaporative Deposition of Aluminum Coatings and Shapes with Grain Size Control
}

\author{
A.F. Jankowski, J.P. Hayes
}

This article was submitted to International Conference on Metallurgical Coatings and Thin Films San Diego, CA, April 28 - May 2, 2003

\section{February 19, 2003}

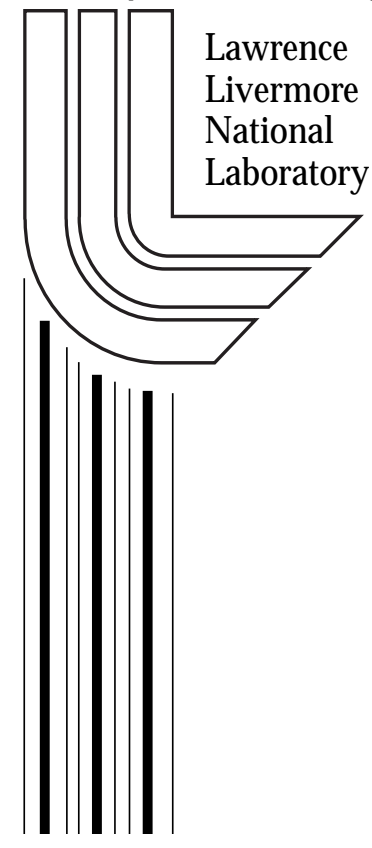




\section{DISCLAIMER}

This document was prepared as an account of work sponsored by an agency of the United States Government. Neither the United States Government nor the University of California nor any of their employees, makes any warranty, express or implied, or assumes any legal liability or responsibility for the accuracy, completeness, or usefulness of any information, apparatus, product, or process disclosed, or represents that its use would not infringe privately owned rights. Reference herein to any specific commercial product, process, or service by trade name, trademark, manufacturer, or otherwise, does not necessarily constitute or imply its endorsement, recommendation, or favoring by the United States Government or the University of California. The views and opinions of authors expressed herein do not necessarily state or reflect those of the United States Government or the University of California, and shall not be used for advertising or product endorsement purposes.

This is a preprint of a paper intended for publication in a journal or proceedings. Since changes may be made before publication, this preprint is made available with the understanding that it will not be cited or reproduced without the permission of the author.

This report has been reproduced directly from the best available copy.

Available electronically at http://www.doc.gov/bridge

Available for a processing fee to U.S. Department of Energy

And its contractors in paper from

U.S. Department of Energy

Office of Scientific and Technical Information

P.O. Box 62

Oak Ridge, TN 37831-0062

Telephone: (865) 576-8401

Facsimile: (865) 576-5728

E-mail: reports@adonis.osti.gov

Available for the sale to the public from

U.S. Department of Commerce

National Technical Information Service

5285 Port Royal Road

Springfield, VA 22161

Telephone: (800) 553-6847

Facsimile: (703) 605-6900

E-mail: orders@ntis.fedworld.gov

Online ordering: http://www.ntis.gov/ordering.htm

OR

Lawrence Livermore National Laboratory

Technical Information Department's Digital Library

http://www.llnl.gov/tid/Library.html 


\begin{abstract}
The direct deposition of coatings with variable cross-section profiles presents a challenge for the use of physical vapor deposition technology. Coatings with constant and variable cross-section profiles are of interest for advancing the evaluation of material behavior under extreme loading conditions, as for example under high strain rate. The synthesis of a variable cross-section profile by design in the asdeposited condition requires process innovation. It is demonstrated that a thickness gradient in crosssection can be produced when the substrate is exposed to a highly collimated evaporation source. The exposure is governed using a variable position shutter as driven by a computer-controlled stepper motor. An example is shown for aluminum deposition in which the coating thickness varies linearly from one plateau to another forming a wedge shape. To deposit a controlled grain size in coatings as these wedge shapes, first requires an understanding of the affect of time at temperature. An examination of aluminum coatings with constant cross-section reveals that ideal-grain growth behavior is observed from the micron-to-millimeter scale for depositions at temperatures in excess of half the melt point.
\end{abstract}

\title{
INTRODUCTION
}

Metal crystals provide ideal samples as targets for the evaluation of material behavior under extreme loading conditions, e.g., as subject to high strain rates induced by laser-driven compression waves.[1] The use of metal single crystals proves useful in specific experimental designs where the distortion of the crystal lattice under the compression wave is measured using x-ray diffraction. In addition, diffraction simulations can reveal the affect of grain size, which then becomes a desired parameter in specimen preparation. The target samples can range in thickness from several microns to millimeters as required for the specific shock drive with lateral dimensions up to a centimeter. The thicker samples are traditionally prepared by processing of bulk crystals using machining and polishing. 
The growth of coatings for use as free-standing foils and as coated substrates presents a new method for specimen preparation and design as well as a new challenge for physical vapor deposition technology. In a novel target design, a variable cross-section is of interest. Specifically, a cross-section profile is desired wherein a linear transition from one plateau to another plateau produces a wedge shape. In addition, a uniform and fine grain size, i.e. less than $50 \mu \mathrm{m}$, is desired for this sample.

The use of electron-beam evaporation is an established process to systematically produce coatings using deposition rates that can exceed $0.1 \mu \mathrm{m} \cdot \mathrm{s}^{-1}$. The classic zone model for growth of evaporated deposits serves a starting point for selecting the process conditions to produce dense crystalline coatings. Thin and thick film models of growth document the morphological evolution that results from evaporation and sputter deposition processes.[2-4] In brief, the coating process is viewed as a three-step process. First, there is transport of the atoms to the substrate. Second, there is atomic adsorption onto and desorption from the surface along with diffusion over the surface. Third, there is bulk diffusion. For the case of evaporative deposits, it's the surface and bulk diffusion processes that effect grain size.[4] It's seen that the structural zones for growth as specific to evaporation methods are greatly dependent on the temperature $(\mathrm{T})$ of the deposit relative to its melt point $\left(\mathrm{T}_{\mathrm{m}}\right)$. [2] At low temperature, i.e. $0<\left(\mathrm{T} \cdot \mathrm{T}_{\mathrm{m}}{ }^{-1}\right)<0.3$, the structure is composed of loosely bound and tapered columnar grains with nodular shaped domes. At intermediate temperature, i.e. $0.3<\left(\mathrm{T} \cdot \mathrm{T}_{\mathrm{m}}{ }^{-1}\right)<0.5$, the columnar structure is densely packed with increased width corresponding to the activation of surface diffusion. At high temperature, i.e. $0.5<\left(\mathrm{T} \cdot \mathrm{T}_{\mathrm{m}}{ }^{-1}\right)<1$, the crystalline structure can become equiaxed as is consistent to the activation of bulk diffusion.

In general, the columnar structure intrinsic to vapor deposits coarsens as its temperature increases to the melting point. It's within the context of the zone model description that we investigate the deposition conditions for electron-beam evaporation relevant to the formation of an aluminum single crystal deposit. The present focus will be in the high temperature zone for aluminum coatings deposited 
over the temperature range of $260-540{ }^{\circ} \mathrm{C}$, i.e. $0.57<\left(\mathrm{T} \cdot \mathrm{T}_{\mathrm{m}}{ }^{-1}\right)<0.87$, noting that the $\mathrm{T}_{\mathrm{m}}$ of aluminum equals $660^{\circ} \mathrm{C}$. Experimental results are presented for the evolution of grain size with the electron-beam deposition conditions for aluminum coatings with constant and variable cross-section profiles up to 100 $\mu \mathrm{m}$ in thickness on both mica and lithium flouride substrates.

\section{SAMPLE PREPARATION}

Deposition of aluminum single and poly crystals is desired using a method that is capable of producing a large variation in the grain size $\left(\mathrm{d}_{\mathrm{g}}\right)$ of metals with melt points less than $1200{ }^{\circ} \mathrm{C}$. This criterion leads to the selection of electron-beam evaporation with substrate heating. The conditions for the evaporative deposition of the aluminum coatings are described as follows. The vacuum chamber is cryogenically pumped to a base pressure less than $1.3 \times 10^{-5} \mathrm{~Pa}$, i.e. $1 \times 10^{-7}$ Torr. A 0.9999 pure aluminum target is melted in a $40 \mathrm{~cm}^{3}$ pocket-crucible using an electron-beam operated at $10 \mathrm{kV}$ with a discharge current (i) range of 0.3-0.6 mA. The source-to-substrate distance ranges from 10 to $15 \mathrm{~cm}$. A short separation enables the high deposition rates that are desirable for thick coatings of $100 \mu \mathrm{m}$ or more. A tantalum substrate platen is heated using a resistive boron-nitride heating element. The substrates used are $50-75 \mu \mathrm{m}$ thick mica sheets or $0.5 \mathrm{~mm}$ thick LiF crystals. The substrates are vacuum compatible to temperatures up to $800{ }^{\circ} \mathrm{C}$ for mica and $450{ }^{\circ} \mathrm{C}$ for $\mathrm{LiF}$. Beyond these temperatures the mica delaminates and the LiF softens and flows under its own weight. These limitations place an upper bound on the grain size obtainable when depositing the aluminum coatings at elevated temperature. The substrates are fastened to the platen using a hard mask of molybdenum sheet. The hard mask for mica has $3 \mathrm{~mm}$ by 3 mm openings for the coating deposition and is offset from the substrate using a $125 \mu \mathrm{m}$ thick spacer layer. The hard mask for the $2 \mathrm{~mm}$ by $2 \mathrm{~mm}$ LiF substrates has $1.8 \mathrm{~mm}$ by $1.8 \mathrm{~mm}$ openings. The spacer layer prevents growth of the coating into the hard mask and ensures an accurate measurement of a thermally isolated coating. (There should be no heating or cooling of the substrate by inadvertent 
contact with the metal hard mask.) The deposition rate (r) and coating thickness $\left(\mathrm{t}_{\mathrm{c}}\right)$ are monitored insitu using a calibrated $6 \mathrm{MHz}$ gold-coated quartz crystal. The final coating thickness is measured using a contact profilometer and/or micrometer. The deposition parameters for several aluminum samples are listed in Table 1.

Whereas the baseline temperature of the substrate platen is controlled through feedback monitoring, it's the actual temperature of the coating that determines its morphological evolution. Therefore, in these experiments, a thermocouple placed on the substrate surface is eventually embedded into the coating during the growth process. This thermocouple provides measurement of the actual coating temperature during the deposition process. In addition, thermocouples are attached to the substrate platen. This method of temperature measurement can be important when the substrate is a thermal insulator and for surface conditions under which a high deposition rate can affect the coating temperature as a consequence of source illumination and the heat of condensation.

\section{CHARACTERIZATION \& ANALYSIS}

\section{Coating Temperature}

The coating temperature is different than the substrate platen temperature during the deposition of the aluminum coating. For sample no. 923, the aluminum deposition is initiated at 0 min. by opening the source shutter and concludes at 19 min. It's seen (in Fig. 1) that the substrate platen temperature $\left(T_{s}\right)$ exceeds the coating temperature $\left(\mathrm{T}_{\mathrm{c}}\right)$ during this experiment. Once the deposition is completed, the substrate rapidly cools well below $200^{\circ} \mathrm{C}$, i.e. $0.5 \cdot \mathrm{T}_{\mathrm{m}}$. The rapid cool of the coating should minimize any bulk diffusion effects on the intrinsic grain size of the coating as a consequence of post deposition annealing. To create the conditions for a low coating temperature, as in sample no. 1113, the longer source-to-substrate distance is used to controllably reduce the deposition rate and minimize heat radiated from the melt pool. For this condition, the coating temperature exceeds that of the substrate platen as 
seen by the data listed in Table 1. The temperatures are reported as time averaged over the exposure of the substrate to the evaporation source.

\section{$\underline{\text { Grain Growth }}$}

The aluminum coatings deposited in a planar geometry are imaged using standard optical metallography procedures. The characterization of the microstructure reveals features of the grain structure. Representative images in plan view (Fig. 2a) and cross-section (Fig. 2b) are shown for a polycrystalline sample no. 731. For sample no. 923, a coating with just a few grain boundaries, images are shown in plan view (Fig. 2c) and cross-section (Fig. 2d) as well. All of the coatings are imaged using bright field illumination. A Nomarski imaging condition, i.e. differential interference contrast, is used to accentuate the grain structure. This technique is most useful for the smallest grain sizes, e.g. as for sample no. 1113. The columnar grain size is seen to increase with the temperature of the coating during deposition. Ultimately, there are no grain boundaries visible at the highest coating temperatures, e.g. as for sample no. 920. The lineal intercept method is used to quantify the grain size.[5] A circular test figure of known perimeter $(\mathrm{P})$ is randomly applied to the image of the coating surface at magnification (M). The number $(\mathrm{N})$ of test circle intersections with grain boundaries are counted. The average grain diameter $\left(\mathrm{d}_{\mathrm{g}}\right)$ for cubic grains equals $2.25 \cdot \mathrm{L}$ where the average lineal intercept $(\mathrm{L})$ equals $\mathrm{n} \cdot \mathrm{P}(\mathrm{M} \cdot \mathrm{N})^{-1}$ for a total number (n) of applications.[6] The grain sizes measured are listed in Table 1. The maximum value reported corresponds with the full specimen dimensions.

The use of x-ray diffraction provides an initial characterization of the preferred orientation of the grains in the aluminum coatings. The samples are exposed to monochromatic $\mathrm{Cu} k \alpha \mathrm{x}$-ray radiation in the $\theta / 2 \theta$ mode. The result for sample no. 920 (shown in Fig. 3) is typical for the aluminum coatings. The dominant presence of the (111) and (222) Bragg reflection(s) at $38.33^{\circ}$ and $82.25^{\circ}$, respectively, on the log-scale intensity plot indicates that grain growth occurs along the [111] direction. Although some samples are polycrystalline, the texture of the aluminum coatings appears invariant. 
To further assess the crystal structure that is found from optical examination, Laue backreflection images are taken. White x-ray radiation is generated from a tungsten target illuminated at 30 $\mathrm{kV}$ and $30 \mathrm{~mA}$. The film images the sample surface during a $3 \mathrm{~min}$. exposure at a distance of $30 \mathrm{~mm}$ using a $0.7 \mathrm{~mm}$ diameter aperture for the incident x-ray beam. The pattern formed for the exposure of sample no. 920 (shown in Fig. 4) corresponds to the three-fold rotation symmetry of a face-centeredcubic single crystal with a (111) growth orientation. Many of the (112), (122), (123), (223), (133), and (233) type reflections are labeled on the image. This Laue pattern is symmetric about the (111) pole with minimal distortion of the spot shape. The absence of higher order reflections may be a result of residual defect structure that can be introduced when the coating cools from its deposition temperature, i.e. a consequence of the thermal expansion mismatch between the mica substrate and aluminum coating. For comparison, the Laue images of the polycrystalline samples do not contain any identifiable, patterned Bragg reflections.

An analysis of grain growth can be made since the grain size is measured as function of a statistical isothermal-coating temperature during deposition over a known time interval (t). The grain growth law provides an assessment of the activation energy (Q) needed for grain growth during deposition of the aluminum coatings. The grain growth law relates an isothermal grain size as proportionate to time raised to the power n.[7] For ideal grain growth, n equals 0.5 . Therefore, a linear plot of $T_{c}^{-1}$ versus $\ln \left(\mathrm{d}_{\mathrm{g}}{ }^{2} \cdot \mathrm{t}^{-1}\right)$ should ideally result with a slope equal to $-\mathrm{Q} \cdot \mathrm{R}^{-1}$ where $\mathrm{R}$ is the universal gas constant $\left(2 \mathrm{cal} \cdot \mathrm{K}^{-1} \cdot \mathrm{mol}^{-1}\right)$. A linear regression analysis is used to compute a slope for the linear curve fit to a plot of the data listed in Table 1 (as shown in Fig. 5). The activation energy for ideal grain growth in these aluminum coatings is $48 \mathrm{Kcal} \cdot \mathrm{gm}^{-1} \cdot \mathrm{atom}^{-1}$.

\section{$\underline{\text { Wedge Deposition }}$}

The required use of a $\mathrm{LiF}$ substrate for the wedge-shaped coating, places an upper limitation on the coating temperature as $\mathrm{LiF}$ is found to soften and deform under vacuum above $450{ }^{\circ} \mathrm{C}$. Hence the 
maximum grain size obtainable in the aluminum deposit is limited to $\sim 0.1 \mathrm{~mm}$ under normal evaporation conditions. The creation of the wedge shape is made possible by use of a computer-controlled shutter. A variable position shutter made from a sheet of $0.25 \mathrm{~mm}$ thick tantalum is located $1 \mathrm{~mm}$ below the substrate surface. The shutter is linearly translated in one of two methods, either to progressively open or close the shutter. In the first method, three stages of exposure positions are used to progressively coat the substrate surface with the deposition flux. In the first stage, a $0.50 \mathrm{~mm}$ long by $1.8 \mathrm{~mm}$ wide opening is used to initiate deposition of coating. In the second stage, once the deposition is started, a microstepper opens the shutter an additional $0.8 \mathrm{~mm}$ in length synchronous with the evaporative deposition of $70 \mu \mathrm{m}$ of coating. In the third stage, the shutter is opened the remaining $0.50 \mathrm{~mm}$ in length to expose the entire $1.8 \mathrm{~mm}$ substrate surface for the deposition of the remaining $30 \mu \mathrm{m}$ of aluminum. A potential disadvantage of this progressive-opening method is that unexposed areas of the substrate are not heated by the deposition source that may subsequently produce a large variation in grain size from one plateau to the other. In the second method, the potential disadvantage of a grain size variation is minimized as the shutter is first opened to expose the entire substrate surface to the vapor flux. After $30 \mu \mathrm{m}$ are deposited, the shutter is instantaneously moved $0.55 \mathrm{~mm}$ to reduce the exposed surface area. The shutter is then closed an additional $0.8 \mathrm{~mm}$ synchronously with the remaining deposition of $70 \mu \mathrm{m}$ of coating. In both exposure methods, the rate of progression for the shutter during the deposition process is controlled through a feedback loop with the measured thickness of the deposit as monitored using a 6 MHz oscillating quartz crystal.

By either the shutter opening or closure method, a linear transition from a $30 \mu \mathrm{m}$ lower plateau to a $100 \mu \mathrm{m}$ upper plateau is desired over the central $0.80 \mathrm{~mm}$ of the LiF substrate surface. A contact profilometry trace of sample no. 726 (shown in Fig. 6) demonstrates a wedge coating with the desired shape as generated using the shutter-closure method at a substrate temperature $\left(\mathrm{T}_{\mathrm{s}}\right)$ of $223 \pm 9{ }^{\circ} \mathrm{C}$ and a deposition rate of $95 \mathrm{~nm} \cdot \mathrm{s}^{-1}$. The upper plateau at the $0.0 \mu \mathrm{m}$ vertical position and $-0.05 \mathrm{~mm}$ horizontal 
position (shown in Fig. 6) is the starting point for the profile trace. At a horizontal position of $0.35 \mathrm{~mm}$, the $65 \mu \mathrm{m}$ vertical descent down the slope of the wedge shape progresses to a horizontal position of 1.2 $\mathrm{mm}$. At the horizontal position of $1.6 \mathrm{~mm}$, the final $30 \mu \mathrm{m}$ descent to the surface of the LiF substrate is found. A minimal grain-size variation from one plateau to the other is anticipated since the coating (and a uniform temperature) was initiated simultaneously over the entire substrate surface. Although the coating temperature $\left(T_{c}\right)$ was not measured for this wedge deposition, the measured grain sizes of $13.0 \pm$ $1.6 \mu \mathrm{m}$ at the lower plateau and $21.2 \pm 2.7 \mu \mathrm{m}$ at the upper plateau are consistent with the grain size (at less than $50 \mu \mathrm{m}$ ) and narrow size distribution desired for the wedge coating. In addition, the narrow grain-size range of 13 to $21 \mu \mathrm{m}$ measured is consistent with the trends of grain size variation listed in Table 1 as well as the data plotted in Fig. 5 for a uniform temperature during deposition of the coating.

\section{SUMMARY}

A grain size dependence on coating temperatures (above half the melt point) is found in the evaporative deposition of aluminum in accordance with ideal grain-growth behavior. In general, the present findings are consistent with the zone model for the growth of vapor deposits as a fully dense microstructure is produced for temperatures above half the melt point $\left(0.5 \cdot \mathrm{T}_{\mathrm{m}}\right)$. A columnar growth structure persists to a coating temperature in excess of $0.78 \cdot \mathrm{T}_{\mathrm{m}}$ for aluminum. The deposition of single crystal aluminum grains is confirmed from Laue patterns and seen for coating temperatures that exceed $530^{\circ} \mathrm{C}$, i.e. $>0.85 \cdot \mathrm{T}_{\mathrm{m}}$. The grain size and temperature data quantitatively defines the zone boundary for initiating single crystal growth in vapor deposited aluminum coatings.

The synthesis of coatings with a variable cross-section profile and a narrow grain size distribution by design (for material behavior studies under extreme loading conditions) is shown possible through the use of electron beam evaporation with a variable position shutter. The position of the shutter is computer controlled to produce a demonstrated shape as a wedge. Although the substrate 
temperature is traditionally used as a reference point, the current findings show that measurement of the actual coating temperature is required for accurate control of grain size in the coating.

\section{ACKNOWLEDGMENTS}

The authors thank Ann Bliss and Bob Vallier for their assistance on the Laue and optical imaging, respectively. This work was performed under the auspices of the U.S. Department of Energy by University of California, Lawrence Livermore National Laboratory under contract No. W-7405-Eng48.

\section{REFERENCES}

1. K.T. Lorenz, D. Kalantar, J. Edwards, J.D. Colvin, D.B. Reisman, and B. Remington, Bull. Am. Phys. Soc. 46 (8), 44 (2001).

2. B.A. Movchan, and A.V. Demchishin, Phys. Met. Metallogr. 28, 83 (1969).

3. R.F. Bunshah, J. Vac. Sci. Technol. 11, 633 (1974).

4. J.A. Thornton, J. Vac. Sci. Technol. A 4, 3059 (1986).

5. J.E. Hilliard, Metal Progr. 85, 99 (1964).

6. A.F. Jankowski, and J.F. Shewbridge, Mater. Lett. 4, 313 (1986).

7. R.E. Reed-Hill, Physical Metallurgy Principles (Van Nostrand, New York, 1973) pp. 304-310. 


\begin{tabular}{|c|c|c|c|c|c|c|}
\hline \multicolumn{7}{|c|}{ Table I. Grain Size Control in Aluminum Coatings on Mica } \\
\hline sample no. & $\mathrm{i}(\mathrm{mA})$ & $\mathrm{r}\left(\mathrm{nm} \cdot \mathrm{s}^{-1}\right)$ & $\mathrm{t}_{\mathrm{c}}(\mu \mathrm{m})$ & $\mathrm{T}_{\mathrm{s}}\left({ }^{\circ} \mathrm{C}\right)$ & $\mathrm{T}_{\mathrm{c}}\left({ }^{\mathrm{o}} \mathrm{C}\right)$ & $\mathrm{d}_{\mathrm{g}}(\mu \mathrm{m})$ \\
\hline 1113 & 0.38 & 1.0 & 22 & $204 \pm 13$ & $264 \pm 12$ & $5.4 \pm 0.7$ \\
\hline 1121 & 0.50 & 5.3 & 34 & $321 \pm 16$ & $340 \pm 26$ & $32 \pm 2$ \\
\hline 716 & 0.56 & 77.5 & 79 & $419 \pm 5$ & $414 \pm 10$ & $81 \pm 4$ \\
\hline 731 & 0.56 & 98.0 & 100 & $470 \pm 18$ & $459 \pm 5$ & $128 \pm 9$ \\
\hline 923 & 0.44 & 29.8 & 34 & $542 \pm 12$ & $502 \pm 13$ & $817 \pm 151$ \\
\hline 920 & 0.44 & 23.8 & 34 & $601 \pm 11$ & $535 \pm 12$ & $>2900$ \\
\hline
\end{tabular}




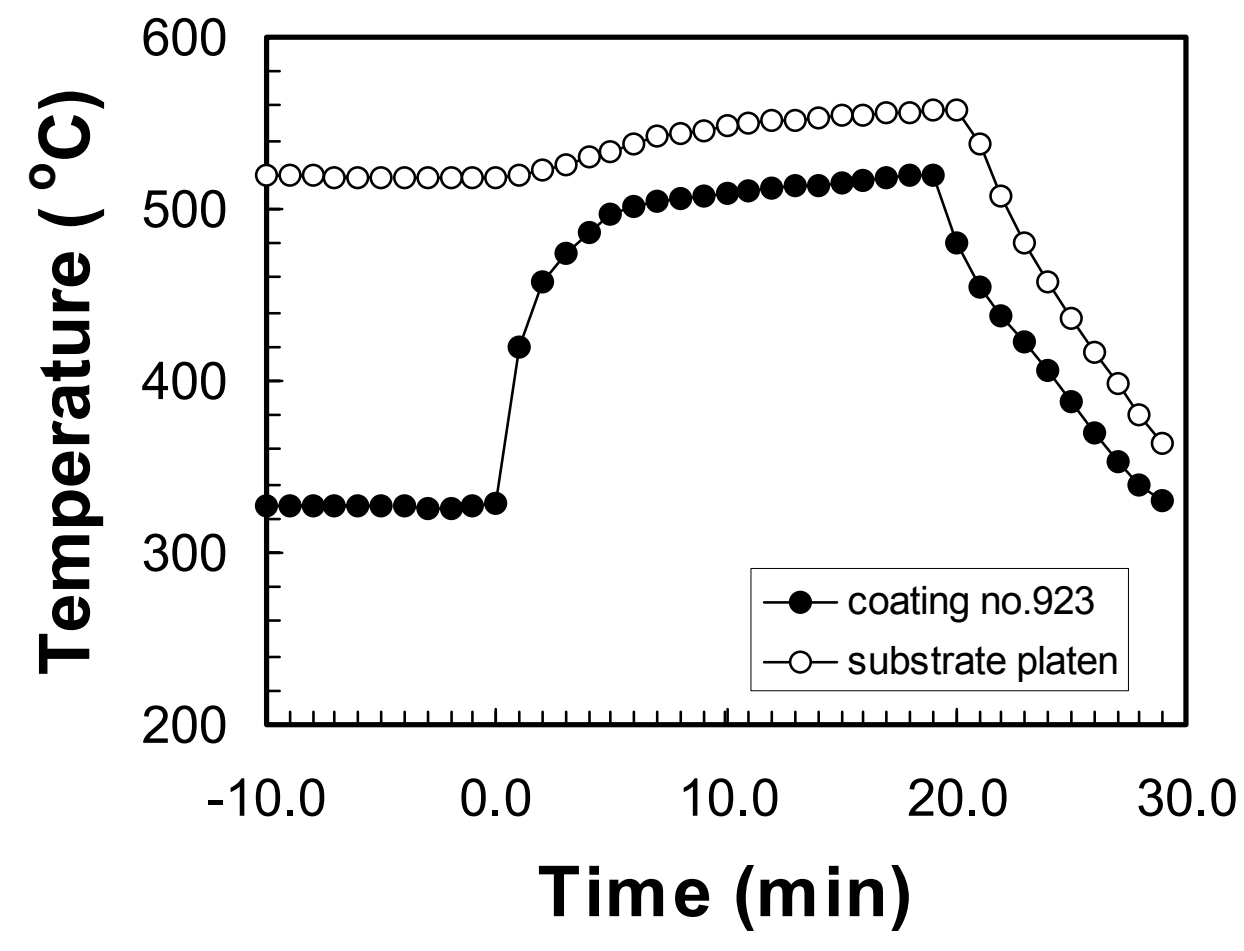

Figure 1. This time-temperature plot displays the thermal history of sample no. 923 as measured in the coating $\left(\mathrm{T}_{\mathrm{c}}\right)$ and on the substrate platen $\left(\mathrm{T}_{\mathrm{s}}\right)$. 


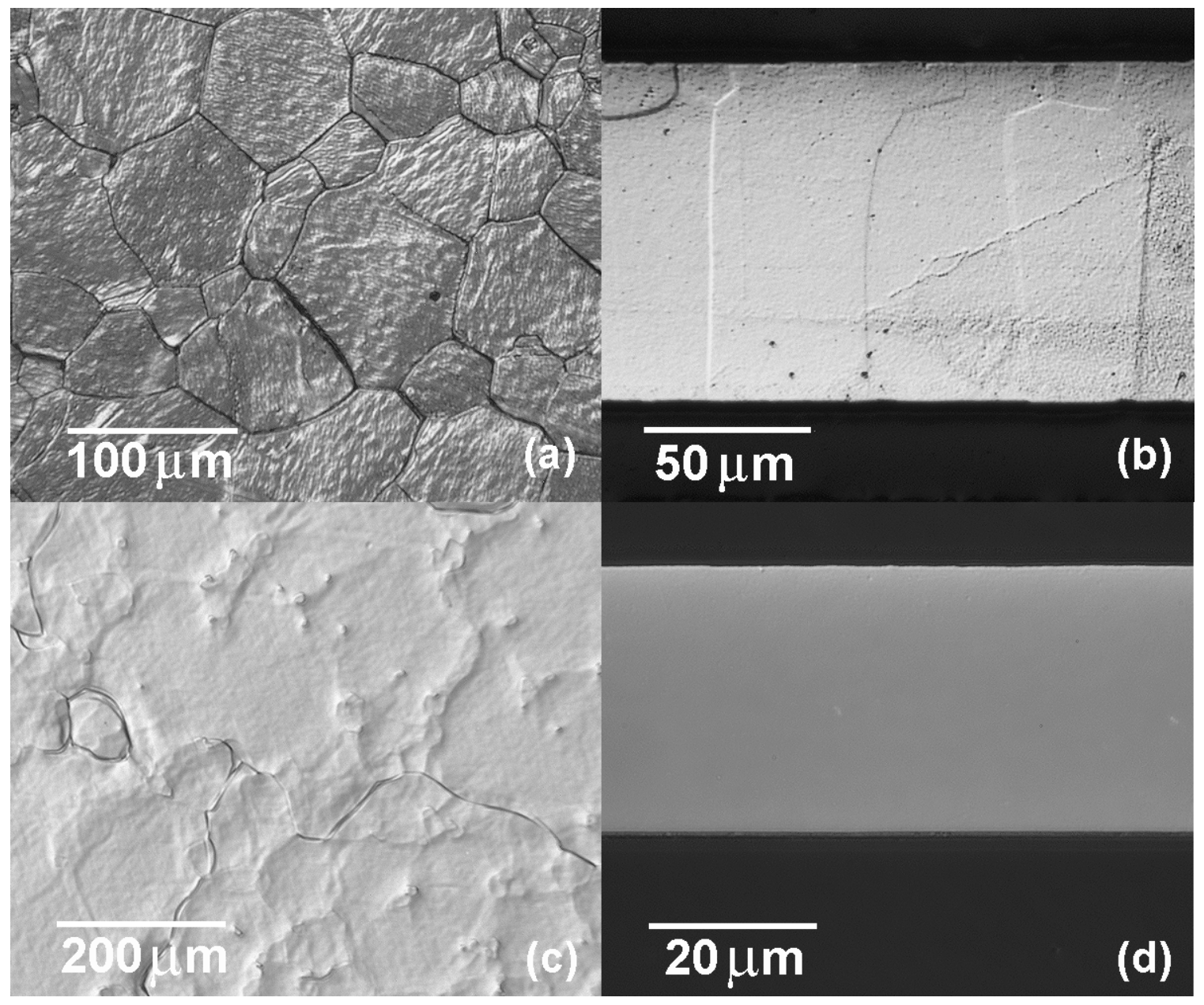

Figure 2. The photomicrographs of sample no. 731 as shown in (a) plan view, and (b) cross-section reveal a fine grained structure, whereas in sample no. 923 only a few grain boundaries are seen in (c) plan view and none in (d) cross-section. 


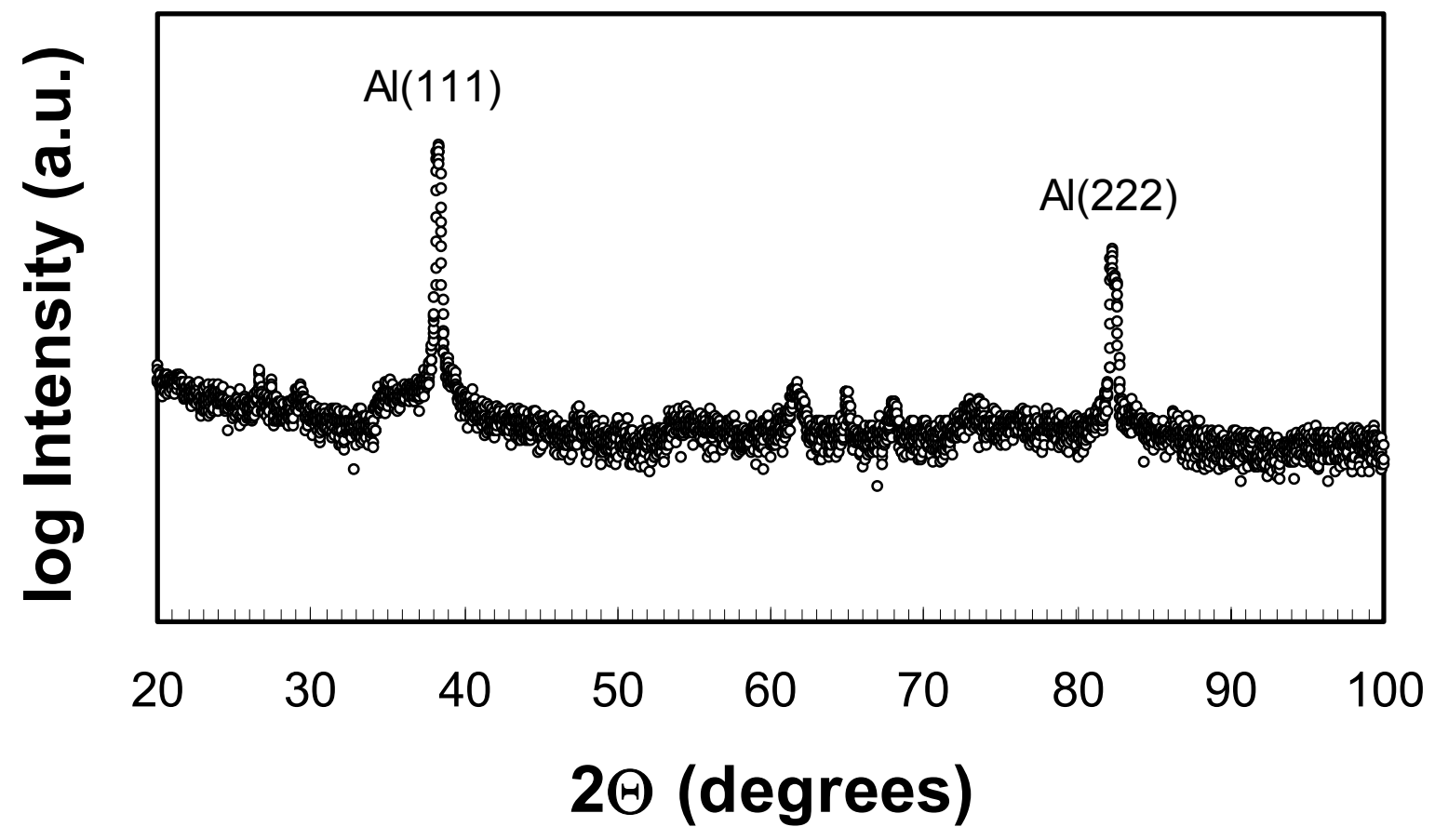

Figure 3. A log-scale plot of intensity versus 2 position in this x-ray diffraction scan of sample no. 920 reveals the single (111) texture of the aluminum coating. 


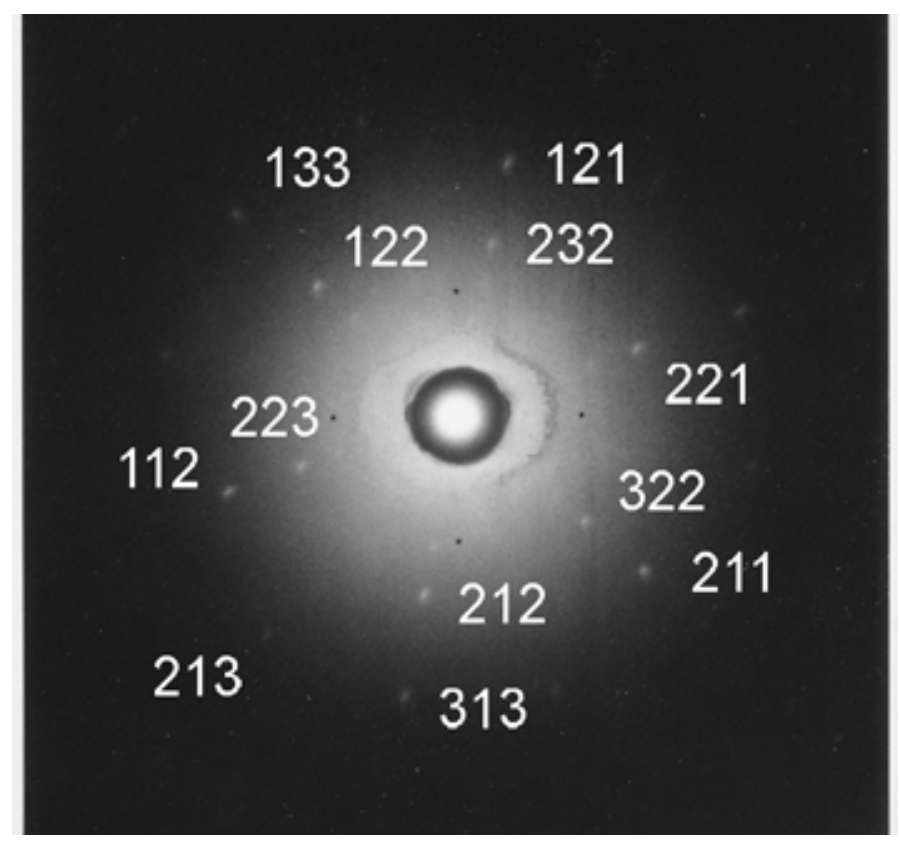

Figure 4. The Laue back-reflection image of sample no. 920 reveals distinct Bragg reflections that indicate a single crystal. 


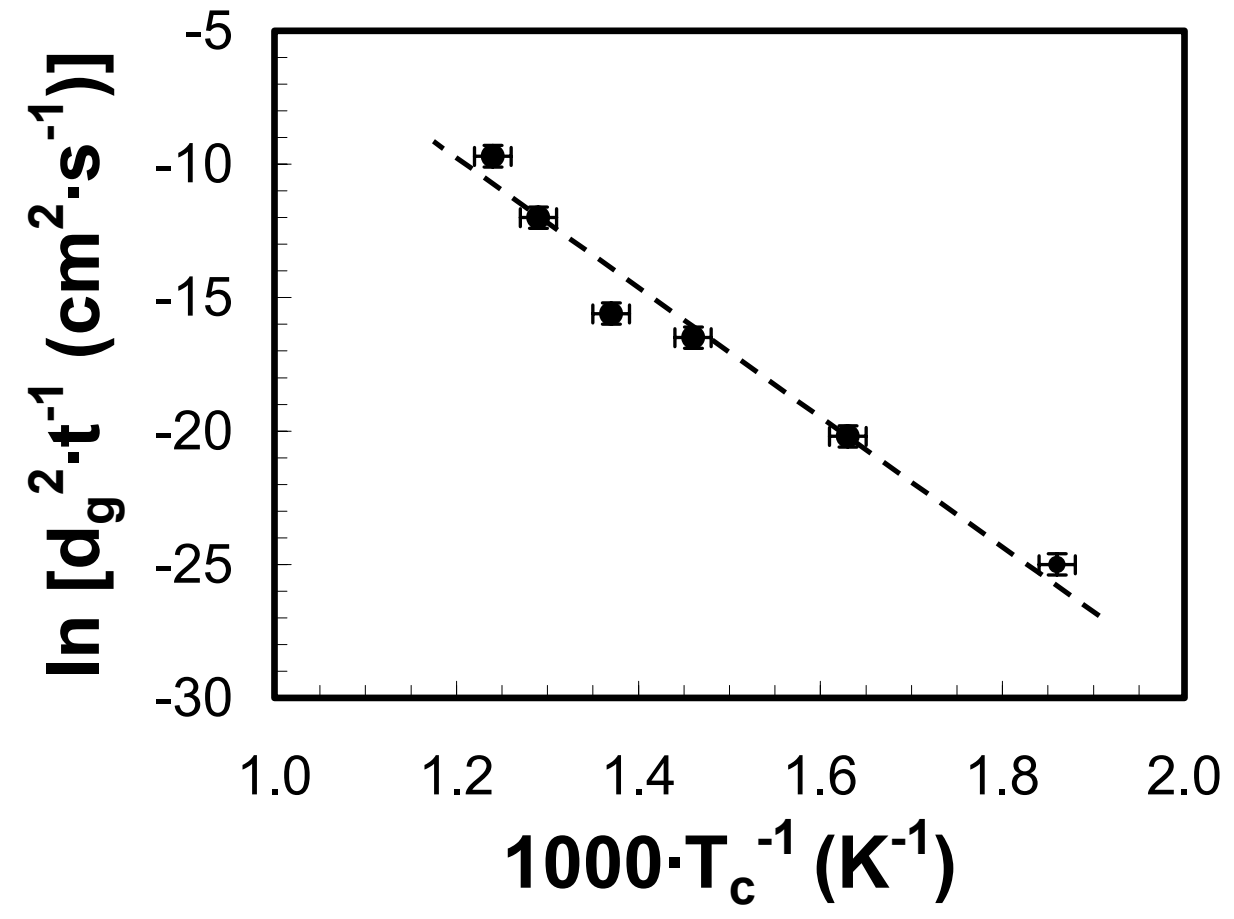

Figure 5. A linear fit to the curve in the plot of $1000 \cdot \mathrm{T}^{-1}$ versus $\log \left(\mathrm{d}_{\mathrm{g}}{ }^{2} \cdot \mathrm{t}^{-1}\right)$ follows the assumption of ideal grain growth for these aluminum coatings. 


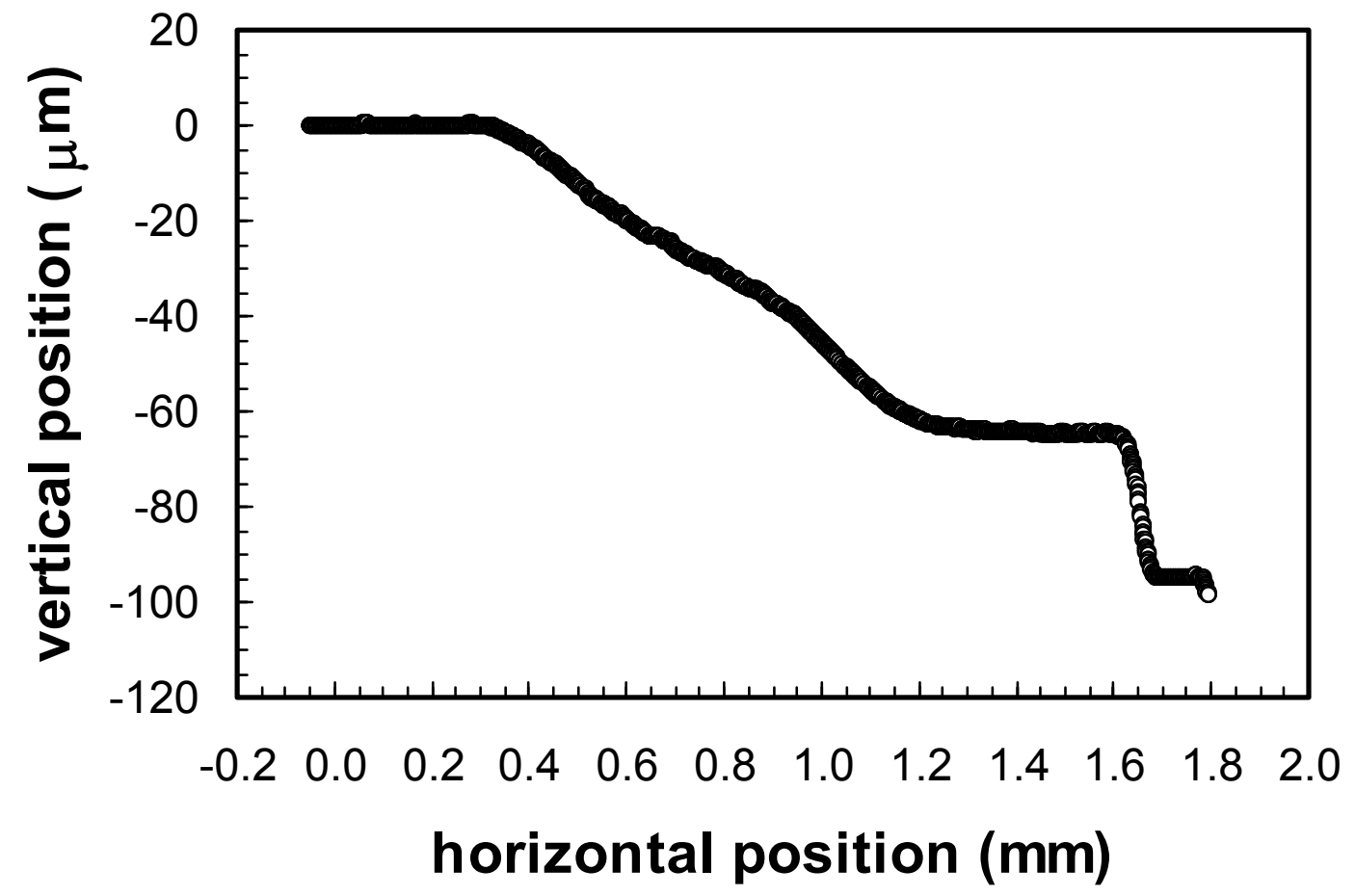

Figure 6. A profilometry trace of the coating height with position across the surface reveals the center wedge shape of sample no. 726 . 